\title{
Neumonía intersticial bilateral en pandemia COVID-19
}

\author{
Juan Cantón-De-Seoane, Blanca Alonso-Martínez, Giancarlo Candela-Ganoza \\ Servicio de Medicina Interna, Hospital Severo Ochoa, Leganés, Madrid, España \\ Recibido: 15/02/2021 \\ Aceptado: 04/05/2021 \\ En línea: 31/08/2021 \\ Citar como: Cantón-De-Seoane J, Alonso-Martínez B, Candela-Ganoza G. Neumonía intersticial bilateral en pandemia CovID-19. Rev Esp Casos Clin Med Intern \\ (RECCMI). 2021 (ago); 6(2): 15-17. doi: 10.32818/reccmi.a6n2a6. \\ Cite this as: Cantón-De-Seoane J, Alonso-Martínez B, Candela-Ganoza G. Bilateral interstitial pneumonia in COVID-19 pandemic. Rev Esp Casos Clin Med Intern \\ (RECCMI). 2021 (Aug); 6(2): 15-17. doi: 10.32818/reccmi.a6n2a6.
}

Autor para correspondencia: Juan Cantón-De-Seoane. juancanton@hotmail.es

\section{Palabras clave \\ $\checkmark$ Artritis reumatoide \\ $\checkmark$ Neumonía intersticial}

\section{Keywords}

$\checkmark$ Rheumatoid arthritis

- Interstitial pneumonia

\section{Resumen}

La artritis reumatoide es una enfermedad sistémica autoinmune caracterizada por la afectación articular con inflamación de la sinovial y destrucción de cartílago articular. La afectación pulmonar es uno de las afectaciones extraarticulares y puede ser la primera manifestación en los pacientes. Presentamos a un varón de 63 años que comenzó con clínica respiratoria y afectación articular siendo diagnosticado de enfermedad pulmonar intersticial secundaria a esta entidad.

Abstract
Rheumatoid arthritis is a systemic autoimmune disease characterized by joint involvement with inflammation of
the synovium and destruction of articular cartilage. Pulmonary involvement is one of the extraarticular affecta-
tions and may be the first manifestation in patients. We present a 63-year-old man who began with respiratory
symptoms with a joint involvement, being diagnosed with interstitial lung disease secondary to rheumatoid ar-
thritis.

\section{Puntos destacados}

- A pesar de encontrarnos en la pandemia por COVID-19, no debemos olvidar el resto de las patologías que pueden dar lugar a afectación pulmonar.

- El diagnóstico de la neumonía intersticial secundaria a artritis reumatoide se basa en la clínica y pruebas de imagen sin ser necesaria normalmente la biopsia.

- El tratamiento empleado es con corticoterapia e inmunomoduladores como el metrotexato.

\section{Introducción}

La actual pandemia COVID-19 ha ampliado nuestro diagnóstico diferencial sobre patologías respiratorias con afectación a otros sistemas de nuestro organismo. Nos ha llevado a pensar en esta causa infecciosa antes que en cualquier otra entidad. Sin embargo, esto nos puede alejar y confundir en la búsqueda de un correcto diagnóstico.

\section{Caso clínico}

\section{Antecedentes y exploración física}

Varón de 63 años de edad derivado a la consulta de Medicina Interna para estudio por tos y fiebre de más de un mes de evolución junto con disnea leve y mialgias generalizadas. Como antecedentes destacaba simplemente ser exfumador de un paquete al día. Trabajó como informático.

Acudió inicialmente a Urgencias con clínica de 7 días de evolución. Por este motivo se le solicitó una radiografía de tórax (Figura 1) en la que se objetivó un patrón pulmonar difuso bilateral. Al mantener buena saturación basal se le dio de alta con sospecha de neumonía bilateral secundaria a COVID-19 recibiendo tratamiento con Cefditoreno y Azitromicina durante 5 días con escasa mejoría.

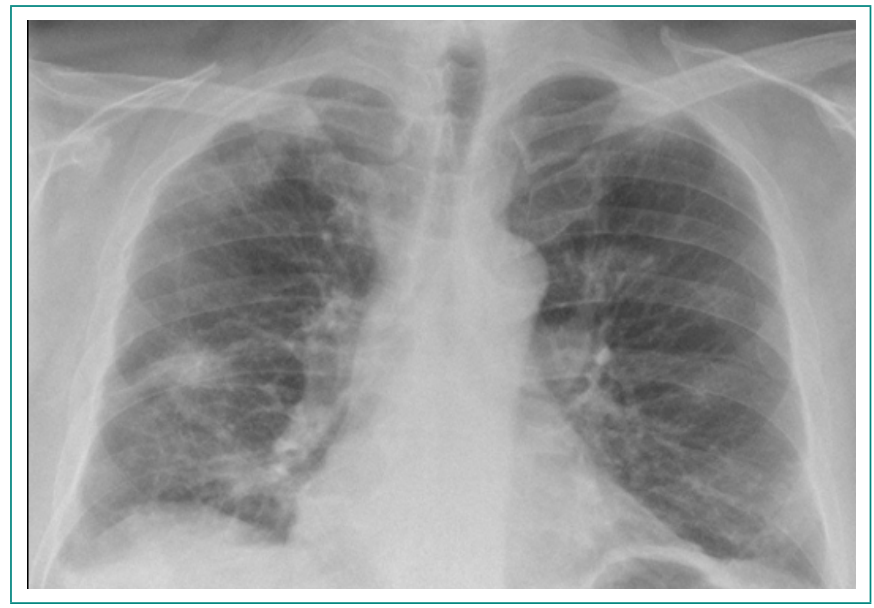

Figura 1. Radiografía de tórax: se observa un patrón pulmonar difuso bilateral. 
El aspirado nasofaríngeo para proteína C reactiva (PCR) de COVID-19 resultó negativo. El resto de la semiología por aparatos no presentaba más síntomas. Negaba contacto con animales o haber realizado viajes al extranjero. No había estado expuesto a humos o productos tóxicos en su trabajo. Valorado en consulta específica de COVID de Medicina Interna con analítica, serologías, nueva PCR y TAC de tórax. Se descarta infección por COVID-19 y se deriva a consulta de alta resolución del mismo servicio para completar el estudio.

\section{Pruebas complementarias}

Se había realizado una analítica básica en la que presentaba una bioquímica con unos niveles normales tanto de creatinina como del perfil hepático, NTproBNP e iones. Sí que se objetivó una elevación de ferritina de $521,8 \mathrm{ng} / \mathrm{mL}$ (30-400) y descenso de hierro de $46 \mathrm{mcg} / \mathrm{dL}$ (57-182) y del porcentaje de saturación de transferrina del 19,89\% (25-60). El hemograma y hemostasia eran estrictamente normales, así como el estudio inmunológico inicial con complemento, espectro electroforético e inmunoglobulinas, además de serología antiSARS-CoV-2 y VIH, que resultaron negativas.

En nuestra consulta se hizo nueva historia clínica sin datos nuevos salvo un episodio hace 5 años de artralgias autolimitado estudiado por Reumatología con autoinmunidad negativa y que no precisó de tratamiento específico.

Revisamos la tomografía axial computarizada (TAC) de tórax. En el TAC se objetivan imágenes de aumento densidad de predominio periférico en ambos pulmones y con un aspecto parcheado. Las imágenes presentaban algunas de ellas densidad vidrio deslustrado, aunque predominaban las características de condensación espacio aéreo con broncograma, también periférico. No se advertían imágenes de adenopatías que por su tamaño fueran sospechosas de malignidad en ningún territorio torácico. Con ventana ósea no se advertían alteraciones relevantes (Figuras 2 y 3 ).

Tras la primera valoración en consulta parecía poco probable la etiología tumoral tóxico/farmacológico o infecciosa. El paciente en todo momento niega factor ambiental o tóxico que pudiese justificar la clínica. Consideramos la patología inflamatoria/autoinmune como la causa más probable. Teniendo en cuenta el antecedente de artralgias sin diagnostico en el pasado y con los hallazgos del TAC decidimos ampliar el estudio con nueva analítica con serologías y autoinmunidad, en el que se objetivó una velocidad de sedimentación globular (VSG) de $112 \mathrm{~mm} / \mathrm{h}$ (0-20), proteína C reactiva (PCR) de $106 \mathrm{mg} / \mathrm{L}(0-5)$, con un factor reumatoide (FR) de 47,2 UI/mL (0-15) y antipéptido cíclico citrulinado (ACCP) positivos de 196,9 UA/mL (0-25). El resto de la autoinmunidad (ANA, ENA, ANCA) fue negativo.

\section{Evolución}

En su segunda visita a la consulta para reevaluación con resultados, el paciente refería persistencia de la sintomatología, pero además se añadió cuadro de un par de semanas de limitación funcional a nivel de ambos hombros con inflamación seguido de la misma afectación en codo derecho y artritis en carpo y dorso de la mano derecha. No refería rigidez matutina.

Sin embargo, por los hallazgos de TAC y la autoinmunidad consideramos como primera posibilidad que se tratase de una neumonía organizada secundaria a artritis reumatoide (AR) por lo que se inició tratamiento con Prednisona de 30 mg diarios y Metotrexato de 15 mg semanales. Presentó mejoría clínica tanto articular como respiratoria, pudiendo disminuir de forma progresiva la pauta de corticoides.

A los dos meses de tratamiento se realizó TAC de tórax de control con resolución, casi total, de las imágenes de aumento de densidad pulmonares bilaterales (Figura 4).

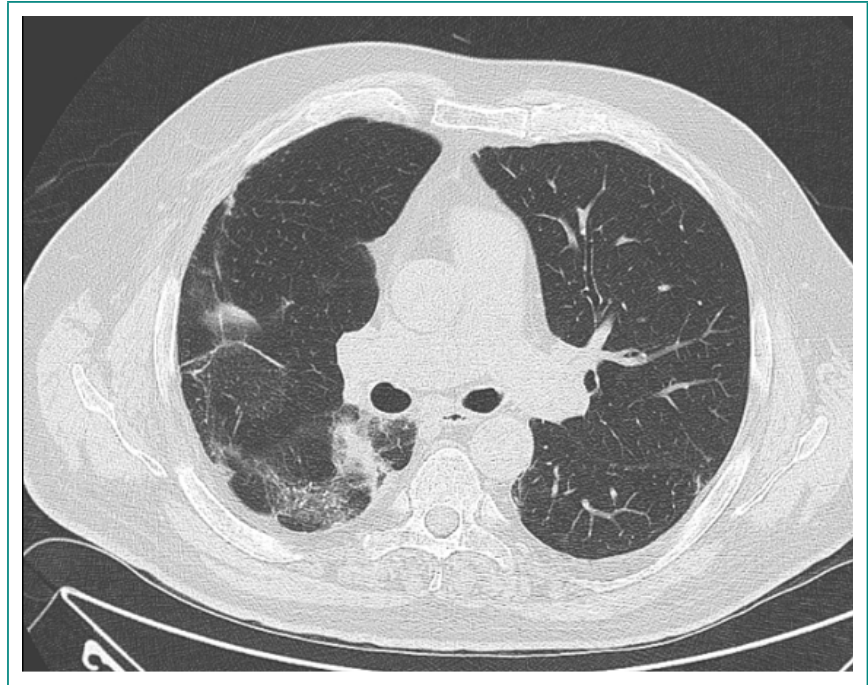

Figura 2. Tomografía computarizada corte axial: se observa aumento de densidad en pulmón derecho parcheado.

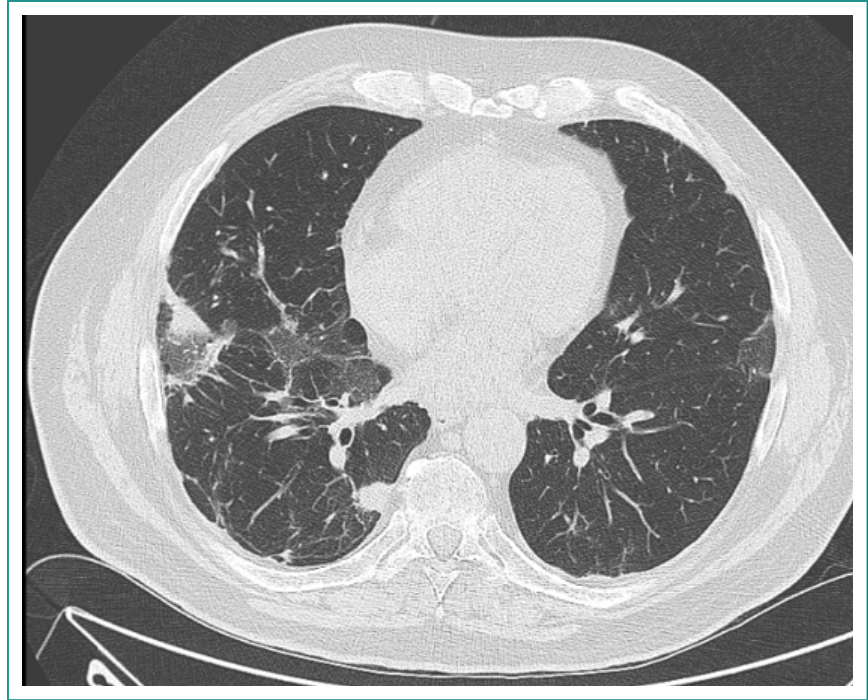

Figura 3. Tomografía computarizada corte axial: se observa afectación bilateral algo más llamativo en pulmón derecho.

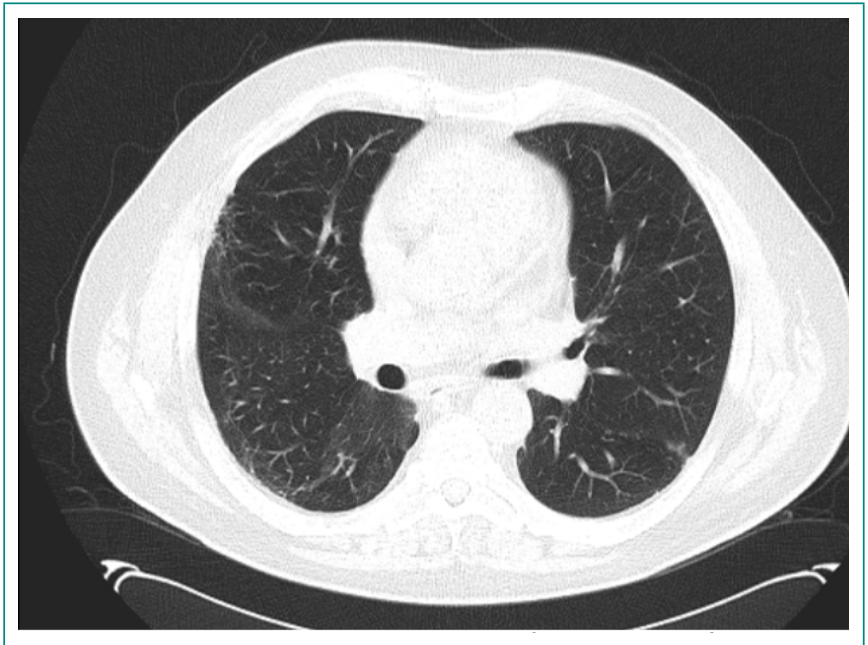

Figura 4. Tomografía computarizada corte axial: presenta una práctica resolución de los infiltrados pulmonares. 


\section{Diagnóstico}

Neumonía intersticial usual secundaria a artritis reumatoide.

\section{Discusión}

La AR es una enfermedad sistémica autoinmune caracterizada por la afectación articular con inflamación de la sinovial y destrucción del cartílago articular Afecta entre el 0,5-1\% de la población siendo más frecuente en mujeres ${ }^{1}$. Los criterios diagnósticos empleados son los ACR/EULAR 2010 precisando un total de 6 puntos para diagnosticarlo (Tabla 1$)^{2}$

\begin{tabular}{|c|c|}
\hline $\begin{array}{l}\text { Afectación articular } \\
\text { (0-5 puntos) }\end{array}$ & $\begin{array}{l}\text { - } 1 \text { articulación grande (0) } \\
\text { - } 2-10 \text { articulaciones grandes (1) } \\
\text { - } 1-3 \text { articulaciones pequeñas (2) } \\
\text { - } \quad \text { 4-10 articulaciones pequeñas (3) } \\
\text { - } \quad \text { Más de } 10 \text { articulaciones (al menos una } \\
\quad \text { pequeña) (5) }\end{array}$ \\
\hline $\begin{array}{l}\text { Serología } \\
\text { (0-3 puntos) }\end{array}$ & $\begin{array}{l}\text { - } \text { FR y ACCP negativos (0) } \\
\text { - } \text { FR o ACCP positivo bajo (2) } \\
\text { - } \text { FR o ACCP positivo alto (3) }\end{array}$ \\
\hline $\begin{array}{l}\text { Reactantes de fase aguda } \\
\text { (0-1 puntos) }\end{array}$ & $\begin{array}{l}\text { - } \text { PCR y VSG normales (0) } \\
\text { - } \text { PCR o VSG elevadas ( } 1 \text { ) }\end{array}$ \\
\hline $\begin{array}{l}\text { Duración de los síntomas } \\
\text { (0-1 puntos) }\end{array}$ & $\begin{array}{l}\text { - Menos de } 6 \text { semanas (0) } \\
\text { - Más de } 6 \text { semanas (1) }\end{array}$ \\
\hline
\end{tabular}

Tabla 1. Criterios diagnósticos de artritis reumatoide.

Es muy común la afectación pulmonar y puede ser la primera manifestación en los pacientes. Aparece hasta en el $67 \%$ de los pacientes con AR siendo la causa de fallecimiento en hasta el 10-20\%. Presenta varios tipos de afectación: 1) a nivel de vía aérea destacan: la artritis cricoaritenoidea y la aparición de bronquiolitis; 2) a nivel pleural y subpleural: presencia de nódulos reumatoides, los cuales son de buen pronóstico y no requieren tratamiento; afectación vascular en forma de vasculitis de vasos pequeños-medianos o, raramente, hipertensión pulmonar; 3) a nivel de pleura lo más frecuente es presencia de pleuritis o derrame pleural exudativo; 4) finalmente puede dar lugar a enfermedad pulmonar intersticial que da lugar a la mayoría de muertes de patología pulmonar ${ }^{3}$.

A su vez, algunos fármacos empleados en el tratamiento de la AR pueden dar lugar a afectación pulmonar destacando el metotrexato o la sulfasalazina que pueden provocar pneumonitis, así como inhibidores TNF alfa que dan lugar a enfermedad pulmonar intersticial ${ }^{4}$.

Centrándonos en la enfermedad pulmonar intersticial que era la que presentó nuestro paciente, son un grupo caracterizado por fibrosis e inflamación del intersticio pulmonar. Tiene una prevalencia entre el 4 y el 50\%. Es más común en hombres de edad avanzada. Los factores de riesgo son el tabaco, la presencia de erosión a nivel articular; datos analíticos como la elevación de VSG y títulos altos de FR y ACCP. Hay varios subtipos histopatológicos siendo los más frecuentes la neumonía intersticial usual y la neumonía intersticial no específica. Otro patrón presente es la neumonía organizada que era el patrón objetivado en nuestro paciente.

La clínica es inespecífica siendo la disnea el síntoma más frecuente. El diagnóstico se basa en la clínica y pruebas de imagen compatibles en pacientes con AR en los que se ha descartado causas tóxicas e infecciosas. La broncoscopia no tiene alteraciones específicas para esta patología y no suele ser necesario salvo para descartar infecciones subyacentes o cuando el diagnóstico no está claro. Raramente se precisa de biopsia para confirmarlo. El tratamiento se basa en la inmunosupresión, siendo los glucocorticoides a altas dosis la primera línea de tratamiento pudiendo añadirse otros inmunomoduladores como el metotrexato, la leflunomida y la azatioprina para disminuir la dosis de corticoide ${ }^{5}$.

Otros tratamientos como la ciclofosfamida o el micofenolato han demostrado beneficio en esto pacientes. Sin embargo, hasta ahora, no existe un tratamiento óptimo para esta patología en el momento actual por lo que su manejo se basa en función de la edad, la progresión pulmonar, la histopatología, la actividad o severidad de la afectación articular, y la presencia de otras manifestaciones extraarticulares ${ }^{6}$.

\section{Bibliografía}

1. Scott DL, Wolfe F, Huizinga TWJ. Rheumatoid arthritis. Lancet [Internet]. 2010; 376(9746): 1094-108. Accesible en: http://dx.doi.org/10.1016/S01406736(10)60826-4 (último acceso abril 2021).

2. Kay J, Upchurch KS. ACR/EULAR 2010 rheumatoid arthritis classification criteria. Rheumatology [Internet]. 2012; 51(suppl 6): vi5-9. Accesible en: https://academic.oup.com/rheumatology/article-lookup/doi/10.1093/ rheumatology/kes279 (último acceso abril 2021).

3. Yunt ZX, Solomon JJ. Lung disease in rheumatoid arthritis. Rheum Dis Clin North Am [Internet]. 2015; 41(2): 225-36. Accesible en: https://linkinghub. elsevier.com/retrieve/pii/S0889857X14001252 (último acceso abril 2021).

4. Esposito AJ, Chu SG, Madan R, Doyle TJ, Dellaripa PF. Thoracic Manifestations of Rheumatoid Arthritis. Clin Chest Med [Internet]. 2019; 40(3): 545-60. Accesible en: https://linkinghub.elsevier.com/retrieve/pii/ S0272523119300310 (último acceso abril 2021).

5. Assayag D, Lee JS, King TE. Rheumatoid arthritis associated interstitial lung disease: a review. Medicina (B Aires) [Internet]. 2014; 74(2): 158-65. Accesible en: http://www.ncbi.nlm.nih.gov/pubmed/24736263 (último acceso abril 2021).

6. Cassone G, Manfredi A, Vacchi C, Luppi F, Coppi F, Salvarani C, et al. Treatment of Rheumatoid Arthritis-Associated Interstitial Lung Disease: Lights and Shadows. J Clin Med [Internet]. 2020; 9(4): 1082. Accesible en: https://www.mdpi.com/2077-0383/9/4/1082 (último acceso abril 2021). 